\title{
Bradyarrhythmias secondary to topical levobunolol hydrochloride solution
}

\author{
This article was published in the following Dove Press journal: \\ Clinical Interventions in Aging \\ 13 October 2014 \\ Number of times this article has been viewed
}

\author{
Lianjun Lin* \\ Yuchuan Wang* \\ Yan Chen \\ Meilin Liu \\ Geriatric Department, Peking \\ University First Hospital, Beijing, \\ People's Republic of China \\ *These authors contributed equally \\ to this work
}

\begin{abstract}
An 88-year-old man was admitted with fatigue, dizziness, and heart palpitations. Both the electrocardiogram and Holter confirmed the existence of sinus bradycardia and sinus arrest. One hour prior to the onset of symptoms, he received levobunolol hydrochloride solution topically. The levobunolol hydrochloride solution was discontinued and the bradycardia resolved. He was diagnosed as having intermittent sinus bradycardia and sinus arrest, induced by topical $\beta$-blocker therapy. Levobunolol hydrochloride solution is an effective therapy for ocular hypertension, probably by reducing aqueous fluid production. However, it can induce cardiac side effects such as bradyarrhythmia and should be used with caution in elderly patients or patients with cardiac disease.
\end{abstract}

Keywords: bradycardia, topical $\beta$-blocker, the elderly, glaucoma

\section{Introduction}

Topical $\beta$-blocker solution is a useful treatment for glaucoma, but it may be an unrecognized and neglected reason for bradycardia for frail geriatric patients. Levobunolol hydrochloride solution, a commonly prescribed medication for patients with glaucoma, contains $5 \mathrm{mg}$ levobunolol hydrochloride/mL. Rarely, the proarrhythmic adverse effect may occur in elderly frail patients or patients with cardiac disease. Here, we report an interesting and thought-provoking case of symptomatic bradycardia following topical administration of levobunolol hydrochloride solution, in an old frail patient, symptoms, which resolved after discontinuation of this eyedrop.

\section{Case report}

An 88-year-old man was admitted to the hospital with abdominal pain. His past history included coronary heart disease for which he underwent percutaneous coronary interventional treatment. He complained of fatigue, dizziness, and heart palpitations, and an electrocardiogram (ECG) demonstrated sinus bradycardia at a rate of $39 \mathrm{bpm}$ (the day of hospitalization; Figures $1 \mathrm{~A}$ and 2A). Holter was taken the second day after being admitted to our hospital, which showed sinus bradycardia, atrioventricular block (first degree), and sinus arrest (Figure 1B). The average heart rate was 54 bpm and the range of heart rate varied from $25 \mathrm{bpm}$ (Figure 3A) to $79 \mathrm{bpm}$. There were 265 episodes of sinus arrest lasting longer than 2 seconds and six arrests longer than 3 seconds (Figure 3A). Serum electrolyte test, complete blood count, thyroid function test, and cardiac marker panel were all within normal limits. After careful review of his history and medication list, the only medication that may be associated with bradycardia was levobunolol hydrochloride solution, which he had been using, one to two drops to each eye, two to three times per day for several years. The lowest heart rate was reached $(25 \mathrm{bpm})$, approximately two hours after instillation of the eyedrops
Correspondence: Meilin Liu Xishiku Avenue 8, Xicheng District, Geriatric Department, Peking University First Hospital, Beijing I00034, People's Republic of China

Tel +86 I0 83572986

Email meilinliu@hotmail.com 


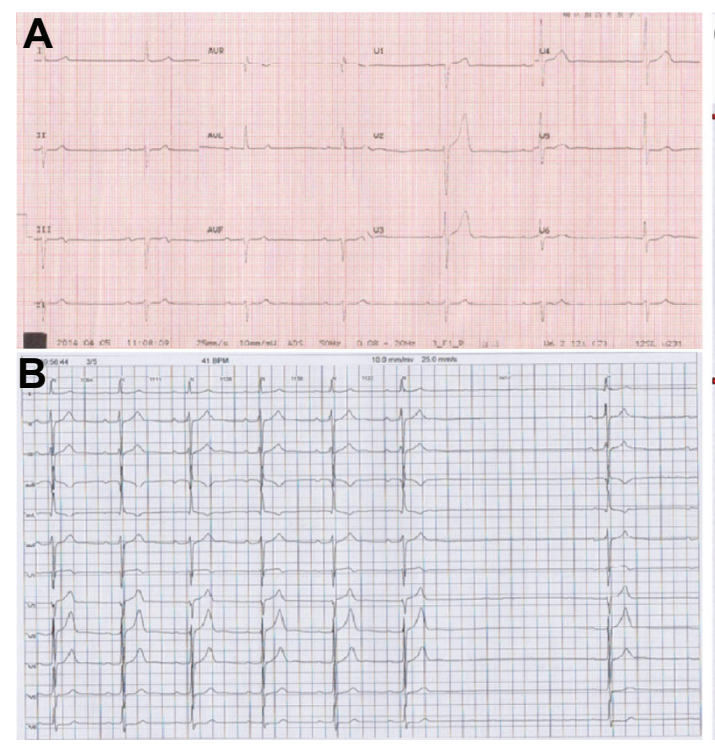

\begin{tabular}{|c|c|c|c|c|c|}
\hline \multirow{2}{*}{$\begin{array}{c}\text { Time } \\
\text { (HH:MM) }\end{array}$} & \multicolumn{3}{|c|}{ HR $(\mathrm{bpm})$} & \multirow{2}{*}{$\begin{array}{r}\text { Arrest } \\
\text { (times) }\end{array}$} & \multirow{2}{*}{$\begin{array}{l}\text { Long RF } \\
\text { (s) }\end{array}$} \\
\hline & Average & Min & Max & & \\
\hline$>07: 07$ & 63 & 51 & 78 & 0 & 0 \\
\hline 08:07 & 60 & 31 & 78 & 8 & 8 \\
\hline |09:07 & 54 & 25 & 69 & 44 & 45 \\
\hline $10: 07$ & 52 & 25 & 59 & 115 & 115 \\
\hline $11: 07$ & 52 & 30 & 58 & 24 & 24 \\
\hline $12: 07$ & 54 & 39 & 62 & 9 & 9 \\
\hline $13: 07$ & 54 & 46 & 63 & 4 & 4 \\
\hline $14: 07$ & 55 & 48 & 67 & o & 0 \\
\hline $15: 07$ & 54 & 39 & 63 & 7 & 7 \\
\hline $16: 07$ & 54 & 49 & 62 & 0 & 0 \\
\hline $17: 07$ & 57 & 49 & 65 & 0 & 0 \\
\hline $18: 07$ & 59 & 33 & 75 & 3 & 3 \\
\hline $19: 07$ & 55 & 34 & 69 & 2 & 2 \\
\hline 20:07 & 55 & 31 & 63 & 3 & 3 \\
\hline 21:07 & 51 & 34 & 56 & 16 & 16 \\
\hline 22:07 & 52 & 26 & 61 & 11 & 11 \\
\hline L9.07 & -52 & 45 & 72 & 5 & 5 \\
\hline $00: 07$ & 53 & 46 & 66 & 0 & o \\
\hline $01: 07$ & 51 & 46 & 56 & 2 & 2 \\
\hline $02: 07$ & 55 & 48 & 72 & 0 & o \\
\hline $03: 07$ & 53 & 49 & 60 & 2 & 2 \\
\hline $04: 07$ & 52 & 47 & 65 & 5 & 5 \\
\hline $05: 07$ & 50 & 46 & 57 & 4 & 4 \\
\hline $06: 07$ & 61 & 43 & 79 & 1 & 1 \\
\hline
\end{tabular}

Figure I ECG results.

Notes: The ECG showed sinus bradycardia, AVB (A) and sinus arrest (B). The symptomatic bradycardia was observed almost I hour after the instillation of levobunolol hydrochloride solution (indicated by red arrows) (C). The red boxes refer to the occurrence of bradycardia.

Abbreviations: ECG, electrocardiogram; AVB, atrioventricular conduction block; HR, heart rate; RR, R-R interval; min, minimum; max, maximum; bpm, beats per minute; $\mathrm{H}$, hour; M, minute.
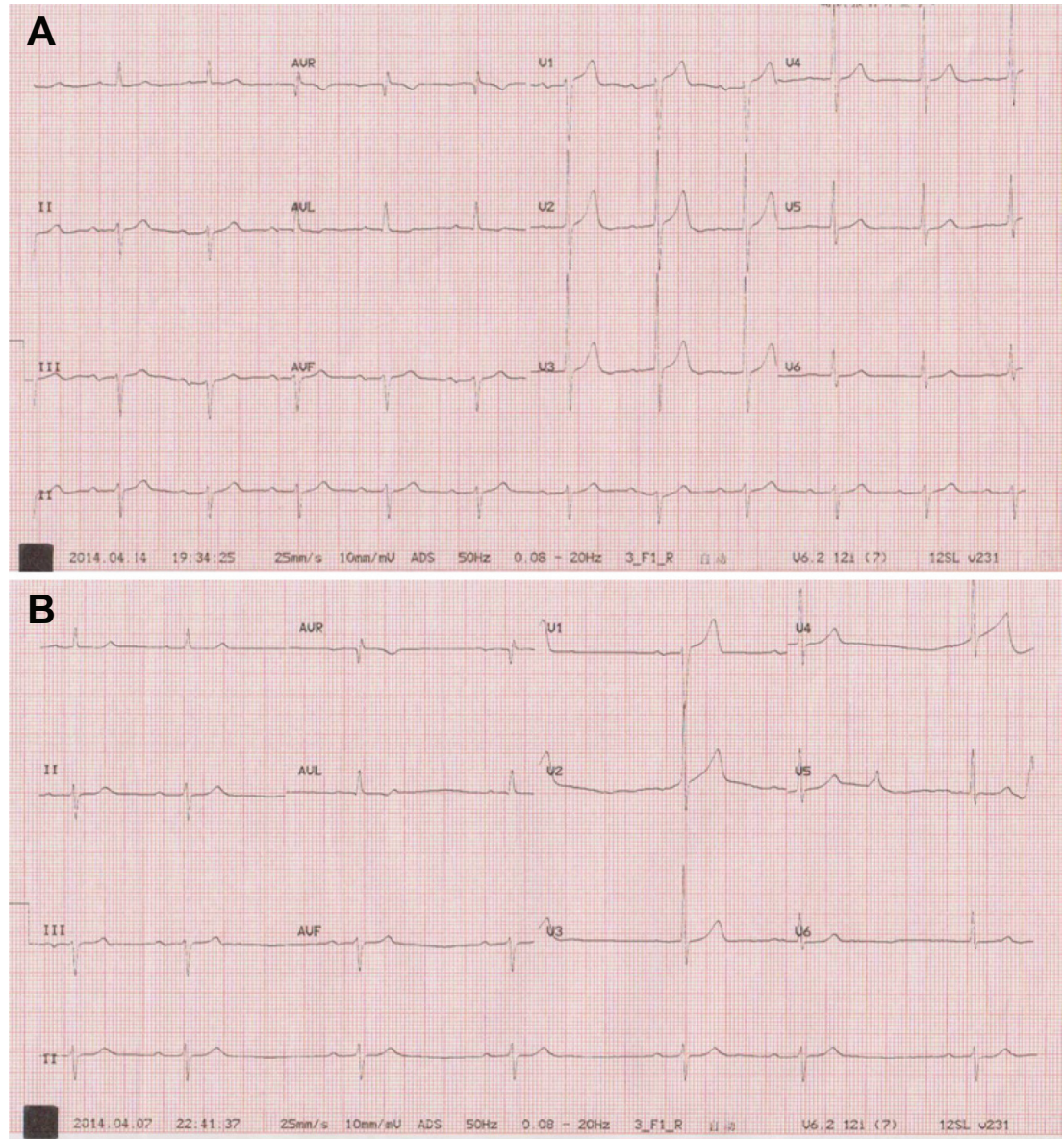

Figure 2 The recovery of heart rhythm shown by ECG.

Notes: ECG demonstrated the recovery of sinus rhythm (A) after withdrawal of levobunolol hydrochloride solution compared to the drug-induced bradycardia (B). Abbreviation: ECG, electrocardiogram. 

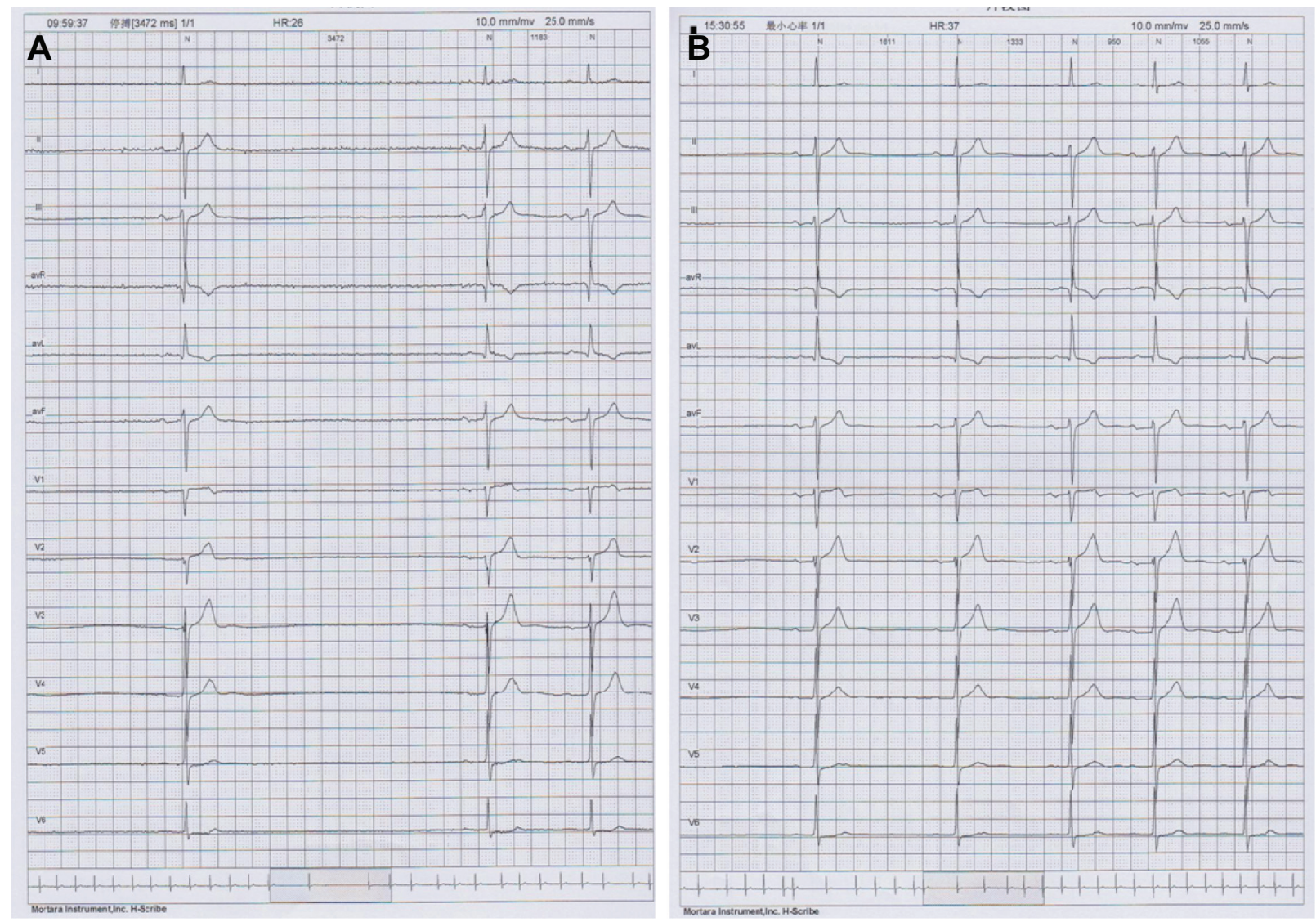

Figure 3 Holter results.

Notes: Holter recorded the minimum heart rate at 25 bpm with a long R-R interval of 3.5 seconds at 9:59 am, about 2 hours after the instillation of levobunolol hydrochloride solution (A). After 48 hours of withdrawal of levobunolol, Holter showed no obvious sinus arrest and the minimum heart rate was 37 bpm (B).

Abbreviation: bpm, beats per minute.

(Figure 1C). Because of the clear relationship between onset of symptomatic bradycardia and the instillation of eyedrops, levobunolol hydrochloride solution was discontinued and replaced with latanoprost eyedrops. After 48 hours, the bradycardia and associated symptoms disappeared. Heart rhythm was re-evaluated after cessation of levobunolol hydrochloride solution by ECG and Holter. ECG showed normal heart rhythm (Figure 2B) and Holter showed sinus rhythm, with an average heart rate of $67 \mathrm{bpm}$ (Figure 3B). The range of heart rate varied from $37 \mathrm{bpm}$ to $117 \mathrm{bpm}$. The number of sinus arrests lasting longer than 2 seconds decreased to eight. Ten days later, the heart rate range recovered to $53 \mathrm{bpm}$ to $100 \mathrm{bpm}$ with an average heart rate of $73 \mathrm{bpm}$, and the sinus arrest disappeared as shown by Holter.

\section{Discussion}

Glaucoma is a disease of the aging eye and its prevalence increases with age. Most of the medications used to treat this condition are topical eyedrops. Topical $\beta$-adrenoceptor antagonist is one of the most popularly used medications.
Nearly half a century ago, Phillips et al discovered fortuitously that propranolol reduced intraocular pressure (IOP). ${ }^{1}$ Studies about $\beta$-blockers had been carrying out subsequently as treatments of glaucoma. In 1978, timolol was released for general use and many topical $\beta$-blockers have dominated the treatment of glaucoma ever since. ${ }^{2}$

Levobunolol, a nonselective $\beta$-adrenergic blocking agent, has effective ocular antihypertensive effects. Its mechanisms to decrease IOP are probably associated with reducing the inflow of aqueous humor. ${ }^{3}$ After topical administration, the onset time of action is within 1 hour, peaking in 2-6 hours and lasting for 24 hours. Although people seem to believe that the side effect profile of such topical medications may be insignificant because of this local application, and some studies found that the effects on heart rate were minimal, 4,5 its side effect on heart rhythm should be emphasized and paid attention to, especially for the frail geriatric patients.

Topical $\beta$-blockers, when systemically absorbed after topical administration, affect the sympathetic and parasympathetic 
nervous systems of patients and can cause cardiovascular toxicity, especially for elderly people with the long-term use of potentially toxic agents, as reported by Frishman et al. ${ }^{6}$ In order to identify the exact effect of topical $\beta$-blockers on pulse rate, Tattersall et al investigated the resting pulse rates in patients attending a specialist glaucoma clinic. Their study indicated that patients using topical $\beta$-blockers had significantly lower resting pulse rates than those not using $\beta$-blockers and concluded that topical $\beta$-blockers should be used with caution, and routine pulse rate monitoring and review of ophthalmic medication were indicated. ${ }^{7}$ In a study about effects of topical levobunolol on intraocular pressure and heart rate in healthy dogs, levobunolol was found to induce bradycardia. ${ }^{8}$ Similar results were confirmed by study on healthy elderly people. In a study named "Controlled comparison of cardiovascular effects of levobunolol $0.25 \%$ ophthalmic solution and betaxolol $0.25 \%$ ophthalmic suspension" by Samuel E Lewis, ${ }^{9}$ it was found that the healthy elderly volunteers treated with levobunolol showed significantly lower average heart rates during exercise and the postexercise recovery period, compared with people treated with betaxolol or placebo. Case reports also gave us evidence of bradycardia caused by levobunolol. Chun et al reported that topical instillation of levobunolol could cause syncope, first-degree atrio block, and bradycardia in patients. ${ }^{10}$ Timolol, a nonselective $\beta$-adrenoceptor antagonist, was one of the most frequently prescribed first-line topical therapies for the reduction of IOP, and there were more case reports about topical timolol that caused bradycardia due to systemic absorption. ${ }^{11,12}$

In a study about atrioventricular block secondary to topical $\beta$-blockers, 243 patients with atrioventricular block were included and 12 were treated with topical timolol. In seven cases, the sinus rhythm was recovered, and in five cases, a pacemaker was implanted. However, none of them recognized the eyedrops as a cause. ${ }^{13}$ Review of the literature showed that the majority of the patients were the elderly. ${ }^{13}$

However, the reality is that the patients, especially the geriatric patients, may not associate their symptoms with the topical eye medications and consequently may not report the use of such drugs. Patients will seldom inform their physicians about their glaucoma therapy unless they are specifically questioned about the use of "eye medications". ${ }^{14}$ As a result, the symptoms may be mistakenly attributed to the aging process or pathologic coexisting disease. Physicians prescribing levobunolol or other topical $\beta$-blockers must be aware of these possible complications.

So it is important to ask about the use of eyedrops in patients with bradycardia or atrioventricular block and doctors should be particularly cautious when prescribing $\beta$-blockers to old patients or patients with cardiac disease. Monitoring of heart rhythm is essential for patients using $\beta$-blockers.

\section{Conclusion}

In the elderly population or patients with heart disease, levobunolol hydrochloride solution may lead to significant bradycardia, which may be potentially dangerous. Recognition of the possible side effect of topical $\beta$-blocker solution in bradycardia is vital as bradycardia may be reversible after discontinuing the $\beta$-blocker, thus avoiding the need for a permanent pacemaker. ${ }^{9}$ This drug should be administered with caution and its effect should be monitored by a physician. If there is any cardiac side effect, the $\beta$-blocker should be discontinued and alternative anti-glaucoma medications should be considered.

\section{Acknowledgments}

This work was supported by the National Science and Technology Support Program, whose topic is Translational Medicine Research of Treatment Risk and Strategy in the Elderly Population (2012BAI37B05). The authors appreciate the help of Professor Pearl Pai for language editing of this paper.

\section{Disclosure}

The authors report no conflicts of interest in this work.

\section{References}

1. Phillips CI, Howitt G, Rowlands DJ. Propranolol as ocular hypotensive agent. Br J Ophthalmol. 1967;51(4):222-226.

2. Koch-Weser J, Frishman WH. beta-Adrenoceptor antagonists: new drugs and new indications. N Engl J Med. 1981;305(9):500-506.

3. Yablonski ME, Novack GD, Burke PJ, Cook DJ, Harmon G. The effect of levobunolol on aqueous humor dynamics. Exp Eye Res. 1987; 44(1):49-54.

4. Derick RJ, Robin AL, Tielsch J, et al. Once-daily versus twice-daily levobunolol (0.5\%) therapy. A crossover study. Ophthalmology. 1992; 99(3):424-429.

5. Rakofsky SI, Melamed S, Cohen JS, et al. A comparison of the ocular hypotensive efficacy of once-daily and twice-daily levobunolol treatment. Ophthalmology. 1989;96(1):8-11.

6. Frishman WH, Kowalski M, Nagnur S, Warshafsky S, Sica D. Cardiovascular considerations in using topical, oral, and intravenous drugs for the treatment of glaucoma and ocular hypertension: focus on beta-adrenergic blockade. Heart Dis. 2001;3(6):386-397.

7. Tattersall C, Vernon S, Singh R. Resting pulse rates in a glaucoma clinic: the effect of topical and systemic beta-blocker usage. Eye (Lond). 2006;20(2):221-225

8. Scardillo A, Pugliese M, De Majo M, Niutta PP, Pugliese A. Effects of topical $0.5 \%$ levobunolol alone or in association with $2 \%$ dorzolamide compared with a fixed combination of $0.5 \%$ timolol and $2 \%$ dorzolamide on intraocular pressure and heart rate in dogs without glaucoma. Vet Ther. 2010;11(3):E1-E6 
9. Lewis SE. Controlled comparison of the cardiovascular effects of levobunolol $0.25 \%$ ophthalmic solution and betaxolol $0.25 \%$ ophthalmic suspension. J Glaucoma. 1994;3(4):308-314.

10. Chun JG, Brodsky MA, Allen BJ. Syncope, bradycardia, and atrioventricular block associated with topical ophthalmic levobunolol. Am Heart J. 1994;127(3):689-690.

11. Anguita M, Torres F, Giménez D, et al. [Bradyarrhythmias secondary to the use of ophthalmic timolol. A report of 3 cases]. Rev Esp Cardiol. 1992;45(1):71-73.
12. Walia HS, Walia SS, Emanuel ME. Sick sinus syndrome associated with topical timolol maleate instillation. J Pharmacol Pharmacother. 2011;2(4):300-302.

13. Rubin LJM, Hevia NS, Veganzones BA, Barriales AV. [Atrioventricular block secondary to topical ophthalmic beta blockers]. Rev Esp Cardiol. 1999;52(7):532.

14. Barber BL, Santanello NC. Relating spontaneous adverse experience reports to scores on a questionnaire querying tolerability. Int $J$ Clin Pharmacol Ther. 1995;33(11):598-604.
Clinical Interventions in Aging

\section{Publish your work in this journal}

Clinical Interventions in Aging is an international, peer-reviewed journal focusing on evidence-based reports on the value or lack thereof of treatments intended to prevent or delay the onset of maladaptive correlates of aging in human beings. This journal is indexed on PubMed Central, MedLine,
Dovepress

CAS, Scopus and the Elsevier Bibliographic databases. The manuscript management system is completely online and includes a very quick and fair peer-review system, which is all easy to use. Visit http://www.dovepress. $\mathrm{com} /$ testimonials.php to read real quotes from published authors. 